\title{
Interação com os pais e o uso do espaço por um infante de Alouatta fusca (Geoffroy Saint-Hilaire, 1812) em cativeiro
}

\author{
Fernanda Keley Silva Pereira NAVARRO ${ }^{1}$, Rodrigo Diana NAVARRO², Valéria do Socorro PEREIRA³, \\ Flávio Henrique Guimarães RODRIGUES ${ }^{4}$
}

\begin{abstract}
RESUMO
Os primatas são animais que possuem elo social entre a mãe e sua prole, diferente de outras ordens de mamíferos. A sobrevivência do infante primata é completamente dependente do cuidado provido por membros de seu grupo social, particularmente do cuidado materno. O objetivo deste estudo foi analisar a utilização do recinto por um infante de bugio e sua proximidade com os pais. O grupo de bugios era composto por um casal de adultos e seu filhote fêmea com quatro meses de idade. O período de observaçóes foi de agosto a dezembro/2006, perfazendo uma média de 96 horas de esforço de amostragem. O método de observaçáo foi o animal focal com registro instantâneo, com intervalos de 30 segundos durante uma hora por dia. O local do estudo foi o recinto de exposição da Fundação Zoo-Botânica de Belo Horizonte, com $7 \mathrm{~m}$ de altura, $6 \mathrm{~m}$ de largura, $7 \mathrm{~m}$ de profundidade com presença de paisagismo interno. As observaçóes revelaram um contato maior do infante com a mãe em relaçáo ao pai e um distanciamento significativo $(\mathrm{P}<0,05)$ do filhote em relaçáo ao contato materno, com o aumento da idade e maior independência. O local mais utilizado durante os três primeiros meses de cativeiro foi a pérgola. No mês de dezembro, período de maior pluviosidade, o filhote aumentou interaçôes ventrais com a mãe, e permaneceu mais tempo no cano. As informaçóes obtidas neste trabalho contribuem para um melhor entendimento em relação aos infantes de Alouatta fusca, suas interaçóes sociais e uso do espaço que podem ser utilizados para aprimorar o manejo ex-situ dos animais, criando melhores condiçóes para a estadia dos mesmos em cativeiro, utilizando-se de estruturas adequadas que simulem o ambiente natural, a fim de garantir o bem-estar dos bugios e assim, a sobrevivência da espécie.
\end{abstract}

PALAVRAS-CHAVE: comportamento, desenvolvimento, recinto, primata

\section{Interaction with parents and use of space by an infant of Alouatta fusca (Geoffroy Saint Hilaire, 1812) in captivity}

\begin{abstract}
Primates are social animals that have bond between mother and offspring, unlike other orders of mammals. The survival of an infant primate is completely dependent on the care provided by members of their social group, particularly maternal care. The aim of this study was to analyze the use of premises for an infant of monkey and its proximity to the parents. The group of monkeys was composed of a pair of adult female and her pup at 4 months of age. The observation period was from august to december 2006, making an average of 96 hours of sampling effort. The method of observation was the focal animal with instant record, with 30 second intervals for 1 hour per day. The study site was an exhibition space of the Zoo-Botanical Foundation of Belo Horizonte, $7 \mathrm{~m}$ high, $6 \mathrm{~m}$ wide, $7 \mathrm{~m}$ deep with the presence of internal landscaping. The results revealed greater contact with the infant's mother and father in relation to a significant departure $(\mathrm{P}<0.05)$ compared to the puppy's maternal contact with increasing age and greater independence. The most used during the first 3 months of captivity was the pergola. In December, a period of higher rainfall, the chick ventral increased interactions with the mother, and stayed longer in the barrel. Information obtained here will contribute to a better understanding in relation to infants of Alouatta fusca, their social interactions and use of space that can be used to improve the ex-situ management of animals, creating better conditions for the stay of those in captivity, using appropriate structures that mimic the natural environment, to ensure the welfare of apes and thus the survival of the species.
\end{abstract}

KEYWORDS: behavior, development, enclosure, primate

\footnotetext{
1 Instituto de Biologia, Departamento de Ecologia, Universidade de Brasília, Campos Darcy Ribeiro - Asa Norte, Brasília, Distrito Federal (DF), Brasil - $70919-970$. email: fbionavarro@gmail.com

2 Professor da Faculdade de Agronomia e Veterinária da Universidade de Brasília (UnB), Caixa Postal 4,508, Brasília, DF 70,910-970, Brasil. email: navarrounb@gmail.com

3 Fundação Zoobotânica de Belo Horizonte, Av. Dr Otacílio Negrão Lima, 8000 Pampulha Belo Horizonte - MG, 31365-450. email: vpereira@pbh.gov.br

${ }^{4}$ Professor do Instituto de Ciências Biológica da Universidade Federal de Minas Gerais. Av.Antônio Carlos, 6627 - Pampulha - Belo Horizonte - MG CEP 31270-901. email: rodrigues@icb.ufmg.br
} 


\section{INTRODUÇÃO}

Os animais do Gênero Alouatta Lacépède, 1799 são conhecidos vulgarmente como bugios, roncadores ou guaribas (Miranda 2004). Estão entre os maiores primatas neotropicais com tamanho entre 600 e $650 \mathrm{~mm}$ (sem cauda) e peso de 6 a $10 \mathrm{~kg}$, sendo apenas menores que os monos-carvoeiros, pertencentes ao gênero Brachyteles Spix, 1823, os macacosaranha, Ateles E. Geoffroy, 1806 e os macacos-barrigudos representantes dos gêneros Lagothrix E. Geoffroy, 1812 e Oreonax Thomas, 1927 (Miranda 2004).

Os primatas do gênero Alouatta Lacèpéde, 1799 são os mais folívoros dentre os macacos neotropicais e são, como um todo, chamados de folívoros comportamentais, por não possuírem adaptaçôes morfológicas associados à folivoria como os primatas do Velho Mundo, tais como colobíneos e indriídeos, caracterizados pela alta seletividade na alimentação, preferência por folhas novas, limitação no percurso diário e grande proporçấo do tempo do dia utilizado em descanso. Estas características os capacitam a sobreviver com uma dieta relativamente de baixa qualidade além de ser uma estratégia alimentar fortemente associada ao tamanho do corpo do animal e em conjunto influenciam os tamanhos de grupos e a área de vida destes primatas (Jardim 2005; Miranda e Passos 2004, Gregorim 2006).

Interaçốes sociais como brincadeira, catação, e agressōes são observadas com menor frequência no gênero Alouatta quando comparado com outros primatas. Os bugios são considerados pouco agressivos. As situaçóes de agressão mais intensas foram observadas entre machos disputando dominância nos grupos e entre machos e fêmeas adultas residentes e indivíduos extra grupo (Jardim 2005).

Os primatas são animais que possuem elo social entre a mãe e sua prole, diferente de outras ordens de mamíferos. A sobrevivência do infante primata é completamente dependente do cuidado provido por membros de seu grupo social, particularmente do cuidado materno. Observando e interagindo com a mãe, o infante aprende o que comer, o que temer, para quem se submeter, onde caminhar, dormir e beber. Em adição, a mãe representa uma fonte de termorregulação, cuidado e a defesa contra predadores e outros agressores. Com o passar do tempo, o infante progressivamente inicia independência da mãe, adquirindo vantagens biológicas e psicológicas importantes, por exemplo, familiaridade com seu meio físico e social. Além do cuidado materno, investimentos paternos e outras formas de cuidado podem estar presentes em várias espécies dependendo de seus sistemas sociais (Miranda et al. 2005).

Atualmente, a fragmentação dos habitats é um dos problemas em termos de conservação ambiental não só pelos efeitos que ocasiona, mas principalmente pela rapidez do processo e dificuldade de ser revertido. Convém salientar que as dificuldades para a preservaçáo das espécies em declínio tornam-se progressivamente maiores à medida que as populaçôes diminuem e tornam-se mais isoladas, tendendo à irreversibilidade (Mendes 1989).

Dentre os primeiros estudos a respeito de guaribas em cativeiro, observava-se que estes animais suportavam mal este ambiente apesar de todos os cuidados com que fossem cercados. No Jardim Zoológico, anexo ao Museu Paraense Emílio Goeldi, embora alojados em viveiros espaçosos inteiramente de tela de arame, contendo árvores vivas e água corrente, alimentada com ramos novos de embaubeira (Cecropia sp), dentro de um período mais ou menos longo, definhavam e morriam, ou mesmo com todas as aparências de uma saúde florescente, sucumbiam subitamente. Apanhados jovens tornavam-se mansos e até relativamente alegres, mas nem assim era lícito contar que viessem a viver muito tempo (Lima 1944).

A alta frequência de mortalidade em cativeiros tem produzido um paradoxo no momento em que Alouatta é o primata do Novo Mundo mais frequentemente estudado no campo, porém há pouco estudo de observaçóes desses bugios em cativeiro (Rylands et al. 1988). Por se tratar de uma espécie criticamente ameaçada de extinção, juntamente com os poucos estudos a respeito do cuidado parental e desenvolvimento de infante em cativeiro, estudos como este se tornam necessários para um melhor entendimento de infantes da espécie Alouatta fusca (Geoffroy Saint-Hilaire 1812) e também para aprimoramento e/ou elaboração de técnicas de translocação e reintrodução como estratégias de conservação desta espécie em seus habitats naturais. Objetivou-se neste estudo, observar a utilização do recinto por um infante de Alouatta fusca, além de sua interação com os pais.

\section{MATERIAL E MÉTODOS}

O trabalho foi desenvolvido na Fundação Zoo-Botânica

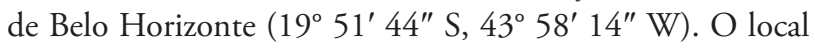
do presente estudo foi o recinto de exposição com $7 \mathrm{~m}$ de altura, $6 \mathrm{~m}$ de largura, $7 \mathrm{~m}$ de profundidade e paisagismo interno composto de vegetação, troncos, cordas, abrigos de madeira, bebedouro, comedouro, mangueira, cano e pérgola (estrutura horizontal feita com postes de eucalipto à $4 \mathrm{~m}$ de altura do chăo). A temperatura da regiáo varia de $16^{\circ}$ a $31^{\circ}$, sendo a média de $21^{\circ}$. O inverno é seco e o verão chuvoso.

Os dados do uso do espaço dentro do recinto e interação do infante com os pais foram coletados no período de agosto a dezembro/2006, perfazendo uma média de 96 horas de esforço de amostragem e um total de 11.616 registros. $\mathrm{O}$ método de anotaçáo dos dados foi o animal focal com registro instantâneo, com intervalos de 30 segundos durante 1 hora por dia (121 registros $\mathrm{h}^{-1}$ ) (Altmann 1974). Os animais 
foram observados seis vezes por semana, sendo as observaçôes distribuídas no período da manhã (8:30 as 9:30 horas) e no período da tarde (14:30 as 15:30 horas), horários estes não coincidentes com o período de alimentaçáo dos animais pelos tratadores. Os bugios eram alimentados três vezes ao dia (8:00; 10:00 e 14:00 horas) com uma dieta constituída de folhas, legumes, frutos e "bolinho" feito com ração de primatas. Um estudo piloto, realizado durante o mês de julho/2006, que constava observações e anotações sobre o uso do espaço em cativeiro e interações do infante com os pais serviu de base para a elaboração do etograma do presente estudo, cuja descrição está representada pelas Tabelas 1 e 2 .

A distribuição entre as classes sexo-etárias dos bugios estudados foi feita pela diferenciação, principalmente, de coloração da pelagem, genitália e tamanho corporal. O infante (Figura 1) nasceu em 22 de abril de 2006, no Jardim Zoológico da Fundação Zoo-Botânica.

As categorias de interação do infante com os pais e os locais dentro do recinto explorados pelo mesmo, durante o período experimental, estão descritos nas Tabelas 1 e 2, respectivamente.

Os dados quantitativos referentes à interação do infante com os pais foram avaliados por meio do teste de Friedman (não-paramétrico) com 5\% de significância, sendo as variáveis analisadas, comparadas entre os meses estudados. Para categorizar os dados referentes aos locais do filhote dentro do recinto aplicou-se o teste Wilcoxon com 5\% de

Tabela 1 - Etograma referente à interação em cativeiro de infante de Alouatta fusca com os pais.

\begin{tabular}{|c|c|c|}
\hline Interação & Categoria & Descrição \\
\hline \multirow{6}{*}{$\begin{array}{l}\text { Distância do infante } \\
\text { em relação à mãe }\end{array}$} & \multirow{3}{*}{ A } & $\begin{array}{l}\text { Infante em contato com a mãe, no } \\
\text { dorso(DM). }\end{array}$ \\
\hline & & $\begin{array}{l}\text { Infante em contato com a mãe, no } \\
\text { ventre (VM). }\end{array}$ \\
\hline & & $\begin{array}{l}\text { Infante em contato com a mãe, ao lado } \\
\text { (LM). }\end{array}$ \\
\hline & B & Infante até 50 cm de distância da mãe. \\
\hline & C & $\begin{array}{l}\text { Infante de } 50 \mathrm{~cm} \text { a } 1 \mathrm{~m} \text { de distância da } \\
\text { mãe. }\end{array}$ \\
\hline & $\mathrm{D}$ & $\begin{array}{l}\text { Infante acima de } 1 \text { m de distância da } \\
\text { mãe. }\end{array}$ \\
\hline \multirow{6}{*}{$\begin{array}{l}\text { Distância do infante } \\
\text { em relação ao pai }\end{array}$} & \multirow{3}{*}{ A } & $\begin{array}{l}\text { Infante em contato com o pai, no } \\
\text { dorso(DM). }\end{array}$ \\
\hline & & $\begin{array}{l}\text { Infante em contato com o pai, no ventre } \\
\text { (VM). }\end{array}$ \\
\hline & & $\begin{array}{l}\text { Infante em contato com o pai, ao lado } \\
\text { (LM). }\end{array}$ \\
\hline & B & Infante até $50 \mathrm{~cm}$ de distância do pai. \\
\hline & C & $\begin{array}{l}\text { Infante de } 50 \text { cm a } 1 \mathrm{~m} \text { de distância } \\
\text { do pai. }\end{array}$ \\
\hline & D & $\begin{array}{l}\text { Infante acima de } 1 \mathrm{~m} \text { de distância do } \\
\text { pai. }\end{array}$ \\
\hline
\end{tabular}

significância. As análises foram realizadas pelo programa computacional STATISTICA 2004. Somado a isto, dados qualitativos obtidos durante as observações foram também descritas.

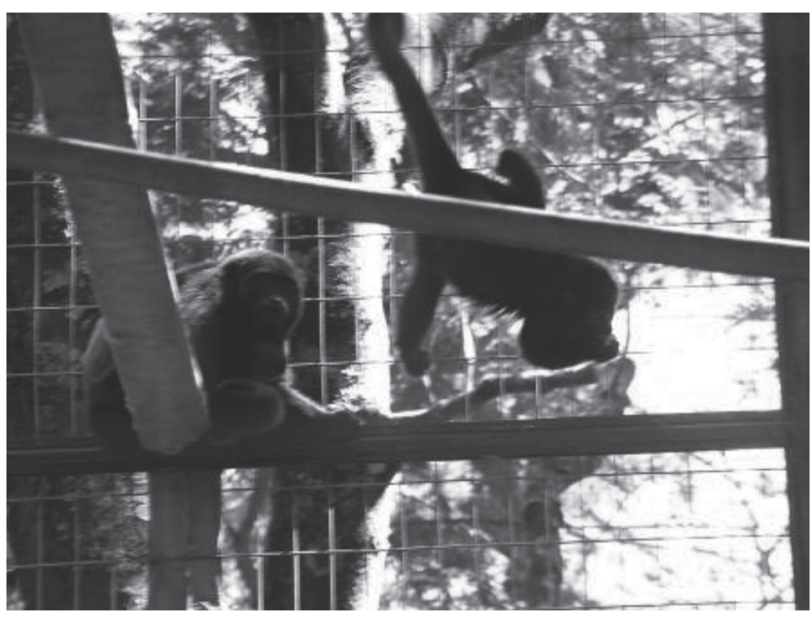

Figura 1- Infante de bugio Alouatta fusca (à direita), na tela do recinto, próximo à mãe (à esquerda), na Fundação Zoo-Botância de Belo Horizonte, MG (Fotografado por V.S. Pereira).

Tabela 2 - Locais de ocupação do infante de Alouatta fusca no recinto.

\begin{tabular}{|c|c|c|}
\hline LOCAL & SIGLA & DESCRIÇAO \\
\hline Cano & CN & $\begin{array}{l}\text { Estrutura de aço, alongada, cujas extremidades } \\
\text { são fixadas em "paredes" distintas do recinto, } \\
\text { funcionando como uma "ponte" retilínea e } \\
\text { estável. }\end{array}$ \\
\hline Mangueira & $M G$ & $\begin{array}{l}\text { Estruturas providas de mangueiras de incêndios, } \\
\text { sendo utilizada como uma "ponte flexível" entre } \\
\text { duas extremidades do recinto. }\end{array}$ \\
\hline Chão & $\mathrm{CH}$ & $\begin{array}{l}\text { Região inferior do recinto, constituído de um solo } \\
\text { com bastante vegetação. }\end{array}$ \\
\hline Comedouro & CD & $\begin{array}{l}\text { Estrutura de madeira, coberta ou não com } \\
\text { presença de um recipiente de alumínio ou } \\
\text { plástico para recebimento dos alimentos providos } \\
\text { pelo zoológico. }\end{array}$ \\
\hline Bebedouro & $\mathrm{BD}$ & $\begin{array}{l}\text { Estrutura de concreto, cheio de água, localizada } \\
\text { próximo ao solo do recinto. }\end{array}$ \\
\hline Pérgola & $P$ & $\begin{array}{l}\text { Estrutura horizontal feita com postes de eucalipto } \\
\text { à } 4 \mathrm{~m} \text { de altura do chão }\end{array}$ \\
\hline Tela & $\mathrm{T}$ & $\begin{array}{l}\text { Estrutura de arame trançado que envolve todo } 0 \\
\text { perímetro do recinto. }\end{array}$ \\
\hline Corda & $\mathrm{CO}$ & $\begin{array}{l}\text { Feixe de fibras vegetais alongados de, de grande } \\
\text { espessura utilizada para amarrar estruturas de } \\
\text { madeira. }\end{array}$ \\
\hline Tronco & TR & $\begin{array}{l}\text { Parte de plantas naturais localizadas dentro do } \\
\text { recinto. }\end{array}$ \\
\hline Abrigo & A & $\begin{array}{l}\text { Estruturas de madeira, em forma de pequenas } \\
\text { casinhas. }\end{array}$ \\
\hline Manobra & M & $\begin{array}{l}\text { Parte mais interna do recinto utilizado para } \\
\text { manejo dos animais capturados, que possui uma } \\
\text { entrada voltada para expositiva do recinto. }\end{array}$ \\
\hline
\end{tabular}




\section{RESULTADOS E DISCUSSÃO}

Durante o período experimental, do quarto ao quinto meses de vida, o infante permaneceu a maior parte do tempo em contato com a máe (45\%) e apenas $4 \%$ acima de $1 \mathrm{~m}$ de distância da mesma. No entanto, entre o primeiro ao terceiro meses de observação, a distância do filhote em relação à mãe foi ampliando significativamente $(\mathrm{P}<0,05)$ com o aumento da idade e maior independência do mesmo (Tabela 3). Em relação ao contato com a mãe (Distância $=0$ ), durante o primeiro mês de observação, o infante posicionou-se $61 \%$ do tempo ao lado da mãe, $22 \%$ no ventre e $17 \%$ no dorso (Tabela 4). Esta tendência da posição de contanto do infante com sua mãe permaneceu a mesma durante os três primeiros meses de observação, porém diferiu significativamente $(\mathrm{P}<$ $0,05)$ em relação ao último mês. $\mathrm{O}$ quarto mês de observação, marcado pela maior pluviosidade, foi considerado o período em que o infante ficou, significativamente $(\mathrm{P}<0,05)$, mais tempo em contato ventral $(62 \%)$ e lateral (30\%) com sua máe (Tabela 4).

Os resultados obtidos no presente estudo com respeito à variação de posição do infante no corpo da mãe e à distância entre ambos em relação à idade são semelhantes ao que é observado em outros estudos dentro do gênero Alouatta, em vida livre. Zacarron (2005) registraram um cuidado excessivo da mãe com o filhote de Alouatta fusca clamitans nos dois primeiros meses, mantendo-o preso ao ventre. A partir do terceiro mês de observação, este pesquisador observou a presença do filhote no dorso materno e no decorrer do quarto mês, alguns deslocamentos sobre troncos de árvores. Mack (1979) notou que, na natureza, durante os primeiros quatro meses, o infante está raramente a mais que $2 \mathrm{~m}$ de sua mãe, entretanto, um infante pode deixar sua mãe mais cedo ao ser levado, acidentalmente, por um outro bugio, ou por ter sido sequestrado ou "emprestado" por sua mãe. Em vida livre, Podgaiski e Jardim (2009) observaram que infantes de Alouatta guariba clamitans com dois a três meses de idade, apresentara apenas $6 \%$ do tempo a uma

Tabela 3 - Distância do infante de Alouatta fusca em relação à mãe durante os quatro meses de observações em cativeiro. A: Infante em contato com a mãe no dorso, ventre ou ao lado; B: Infante até $50 \mathrm{~cm}$ de distância da mãe; C: Infante de $50 \mathrm{~cm}$ a $1 \mathrm{~m}$ de distância da mãe; D: Infante acima de $1 \mathrm{~m}$ de distância da mãe.

\begin{tabular}{lcccc}
\hline Período de & \multicolumn{4}{c}{ Distância do infante de Alouatta fusca em relação à mãe \% } \\
\cline { 2 - 5 } observação* & $\mathrm{A}$ & $\mathrm{B}$ & $\mathrm{C}$ & $\mathrm{D}$ \\
\hline Mês I & $45 \mathrm{~b}$ & $36 \mathrm{~b}$ & $15 \mathrm{a}$ & $4 \mathrm{~b}$ \\
Mês II & $47 \mathrm{~b}$ & $24 \mathrm{~b}$ & $15 \mathrm{a}$ & $14 \mathrm{~b}$ \\
Mês III & $40 \mathrm{~b}$ & $22 \mathrm{~b}$ & $17 \mathrm{a}$ & $21 \mathrm{a}$ \\
Mês IV & $72 \mathrm{a}$ & $13 \mathrm{a}$ & $6 \mathrm{~b}$ & $9 \mathrm{~b}$ \\
\hline
\end{tabular}

* Mês I: Final de Agosto à final de Setembro/2006: Mês II: Final de setembro à final de outubro/2006: Mês III: Final de outubro à final de novembro/2006: Mês IV: Final de novembro à final de dezembro/2006. Médias na mesma coluna com diferentes sobrescritos são significantemente diferentes segundo teste de Friedman $(p<0,05)$. distância de $1 \mathrm{~m}$ da mãe. Miranda et al. (2005) também verificaram, em florestas de Araucária (Araucaria sp), a permanência de $100 \%$ do tempo de um infante Alouatta guariba (Humboldt), com um mês de vida, na região ventral da mãe.

Entre o quinto e sétimo meses de vida, o infante de Alouatta fusca observado neste estudo, começou a se comportar mais independentemente, com brincadeiras de se pendurar e locomoções longe de sua mãe, sendo observados em algumas ocasiôes, até mesmo a rejeição e impedição do infante de se posicionar sobre o dorso de sua mãe. A redução do tempo dedicado ao cuidado parental com o crescimento dos infantes de Alouatta caraya, foi verificado por Albuquerque e Codenotti (2006). A maior independência do infante em relação a sua mãe com o aumento da idade de vida é também notada nas análises de Baldwin e Baldwin (1973). Segundo suas descriçôes, em vida livre, um infante II (Categoria intermediária de infante: animal mais ativo e coordenado, podendo pendurar-se pelo seu rabo e manter uma distância considerável de sua mãe durante algum tempo) pode viajar independentemente da sua mãe durante uma lenta progressão do grupo, mas geralmente permanece a dois metros da mãe. Em ambiente natural, Podgaiski e Jardim (2009) também observaram um menor contato ventral e dorsal do infante (Alouatta guariba clamitans) com a mãe em movimento, principalmente após cinco meses de idade, além de menos de 30\% de contato com a mãe aos 11-12 meses de vida. Estudos de Miranda et al. (2005) corroboram com resultados anteriores, onde foi constatada uma grande independência de infante de Alouatta guariba a partir do quinto mês de idade, com presença de movimentos exploratórios e distantes da mãe.

Devido a maior frequência de chuvas no quarto mês de estudo, entre o sétimo e oitavo meses de vida, o infante permaneceu, significativamente $(\mathrm{P}<0,05)$, mais tempo em

Tabela 4 - Observações de infante Alouatta fusca em contato com os pais durante os quatro meses em cativeiro. DM: Infante em contato com a mãe, no dorso; VM: Infante em contato com a mãe, no ventre; LM: Infante em contato com a mãe, ao lado; DP: Infante em contato como pai, no dorso; VP: Infante em contato com o pai, no ventre; LP: Infante em contato com 0 pai, ao lado.

\begin{tabular}{ccccccc}
\hline & \multicolumn{3}{c}{ Infante em contato com os pais \% } \\
\cline { 2 - 7 } $\begin{array}{c}\text { Período de } \\
\text { observaçãa* }\end{array}$ & \multicolumn{2}{c}{$\begin{array}{c}\text { Infante em contato } \\
\text { com a mãe }\end{array}$} & \multicolumn{3}{c}{$\begin{array}{c}\text { Infante em contato } \\
\text { com o pai }\end{array}$} \\
\cline { 2 - 7 } & DM & VM & LM & DP & VP & LP \\
\hline Mês I & $17 a$ & $22 b$ & $61 a$ & $5 a$ & 0 & $95 a$ \\
Mês II & $8 \mathrm{~b}$ & $12 \mathrm{c}$ & $80 \mathrm{a}$ & $2 \mathrm{a}$ & 0 & $98 \mathrm{a}$ \\
Mês III & $9 \mathrm{~b}$ & $21 \mathrm{~b}$ & $70 \mathrm{a}$ & $0 \mathrm{~b}$ & 0 & $100 \mathrm{a}$ \\
Mês IV & $8 \mathrm{~b}$ & $62 \mathrm{a}$ & $30 \mathrm{c}$ & $0 \mathrm{~b}$ & 0 & $100 \mathrm{a}$ \\
\hline
\end{tabular}

* Mês I: Final de agosto à final de setembro/2006: Mês II: Final de setembro à final de outubro/2006: Mês III: Final de outubro à final de novembro/2006: Mês IV: Final de novembro à final de dezembro/2006. Médias na mesma coluna seguidas de letras diferentes são significantemente diferentes segundo teste de Friedman $(p<0,05)$. 
contato com a mãe $(72 \%)$ em relação aos meses anteriores, e apenas $9 \%$ longe da mãe (acima de $1 \mathrm{~m}$ ) (Tabela 3).

Em um fragmento urbano do Cerrado, Nantes e Rímoli, Acesso em 27/05/2011, observaram que um grupo de bugiospretos (Alouatta caraya) gastou significativamente mais tempo em descanso na estação chuvosa em relação à estação seca, cujo período de alimentação e deslocamentos foram maiores. Zaccaron (2005) verificaram, em uma área remanescente de Mata Atlântica, um agrupamento de indivíduos adultos e filhotes de Alouatta fusca clamitans, durante uma chuva rápida.

Um infante de bugio parece receber com bastante passividade a mãe, que demonstra poucas reaçóes positivas, inclusive poucos cuidados, mas intensa tolerância (Carpenter 1934; Altman 1959; Neville 1972). Durante os primeiros meses de observaçóes pode-se perceber uma maior tolerância da mãe em carregar o filhote pelo dorso. Com o desenvolvimento da capacidade motora, exploratória e percepção ambiental, a mãe do infante mostrou-se intolerante ao mesmo, em situaçóes como carregá-lo pelo dorso e amamentá-lo, com exceção de períodos chuvosos, quando a fêmea adulta protegia o filhote em seu ventre sobre o cano, ou carregava-o no dorso até um dos abrigos do recinto. No estudo de Sousa (2005) sobre Alouatta belzebul (Linnaeus, 1766), as interaçôes sociais amistosas foram comuns entre fêmeas e filhotes e envolviam comportamentos de catação e brincadeiras, onde geralmente os infantes se penduravam nos galhos pela cauda e procuravam tocar ou morder membros de seu próprio corpo ou de sua mãe. Comportamentos semelhantes foram observados neste trabalho onde o infante ao se pendurar em algum dos suportes dentro do recinto (cano, tela, corda) puxava e mordia seus próprios membros ou de sua mãe, que recebia com passividade tais brincadeiras, ou às vezes de seu pai, que respondia com agressividade e intolerância. No entanto, atos de extrema agressividade como aperto ou mordidas no infante não foi observado entre o pai e o filhote. Casos de infanticídio, apesar de raros, podem ocorrer entre primatas do gênero Alouatta e os machos agressores são frequentemente indivíduos extragrupo, imigrantes recente ou machos que ocupam uma posiçáo de dominância sobre a fêmea. A competição por recurso, patologia social é algumas das causas para a ocorrência de infanticídio entre primatas (Aguiar et al. 2005).

O contato direto do infante com o pai foi pouco frequente durante os quatro meses de observação (9-14\%) (Tabela 4). Dentro desta estimativa, nenhum contato ventral foi observado durante os quatro meses de estudo, mas o infante posicionou-se ao lado do pai grande parte do tempo (95100\%) (Tabela 4). Zacarron (2005) também registrou em torno dos quatro meses de idade, a descida do filhote do dorso da mãe e sua direção ao macho adulto, onde permaneceu encostado a ele por alguns minutos, voltando em seguida para perto da máe.
Entre o quarto e sexto meses de vida, pouco contato dorsal com o pai foi verificado (Tabela 4), sendo este, na maioria das vezes, relacionados a brincadeiras de pulo do infante sobre o dorso do pai e a utilização do mesmo como apoio para agarrar objetos do recinto com a intenção de locomover-se. Do quarto ao oitavo meses de idade, o infante permaneceu a maior parte do tempo longe do pai (acima de $1 \mathrm{~m}$ ) (Tabela 5).

As poucas interaçóes paternas observadas neste estudo consistiram de brincadeiras de pulo do infante sobre o dorso do pai, a utilização do corpo do macho adulto como apóio para deslocar-se ou manusear algo, se posicionar ao lado do pai para observar suas açóes (ex: pegar galho fora do recinto), observar e manusear o pelo do pai, puxar e/ou morder o rabo do pai ou algum de seus membros. Como mencionado anteriormente, esta última ação muitas vezes irritava o macho até então em repouso, este procurava fazer o mesmo com o filhote, parecendo um ato de agressão, devido diferença de tamanho do corpo e de força entre ambos, e as sucessivas vocalizaçóes do infante neste momento. No entanto, segundo Clarke et al. 1998, na natureza, cuidados paternos ocorreram entre grupos de Alouatta palliatta (Gray 1848) sem ocorrência de agressóes ou lutas entre os mesmos. No estudo de Miranda et al. (2005), em vida livre, foi observado um infante de Alouatta guariba (Humboldt, 1812) antes de completar um mês de idade, carregado sobre o dorso de um macho juvenil e de um macho subadulto, possíveis irmãos. Em contraste ao analisado no presente estudo, as descriçóes de Baldwin e Baldwin (1973), em ambiente natural, mostram que interaçóes com infantes podem ocorrer, envolvendo animais mais velhos, exceto machos adultos.

Dentre os locais de maior acesso pelo infante dentro do recinto (mangueira, cano, pérgola, tela, corda), notou-se que o filhote, do quarto ao sétimo meses de vida, realizou a maior parte de suas atividades na pérgola, enquanto que entre o sétimo e oitavo mês, o cano foi o locai mais utilizado (Figura 2).

Tabela 5 - Distância do infante de Alouatta fusca em relação ao pai durante os quatro meses de observações em cativeiro. A: Infante em contato com o pai no dorso, ventre ou ao lado; B: Infante até $50 \mathrm{~cm}$ de distância do pai; C: Infante de 50 cm a 1m de distância do pai; D: Infante acima de $1 \mathrm{~m}$ de distância do pai.

\begin{tabular}{lcccc}
\hline & \multicolumn{4}{c}{$\begin{array}{c}\text { Distância do infante de Alouatta fusca em } \\
\text { relação ao pai \% }\end{array}$} \\
\cline { 2 - 5 } & A & B & C & D \\
\hline Mês I & $9 a$ & $26 a$ & $18 a$ & $47 a$ \\
Mês II & $14 a$ & $20 a$ & $17 a$ & $49 a$ \\
Mês III & $10 a$ & $25 a$ & $21 a$ & $44 a$ \\
Mês IV & $14 a$ & $20 a$ & $17 a$ & $49 a$ \\
\hline
\end{tabular}

* Mês I: Final de Agosto à final de Setembro/2006: Mês II: Final de setembro à final de outubro/2006: Mês III: Final de outubro à final de novembro/2006: Mês IV: Final de novembro à final de dezembro/2006. Médias na mesma coluna seguidas de letras diferentes são significantemente diferentes segundo teste de Friedman $(p<0,05)$ 


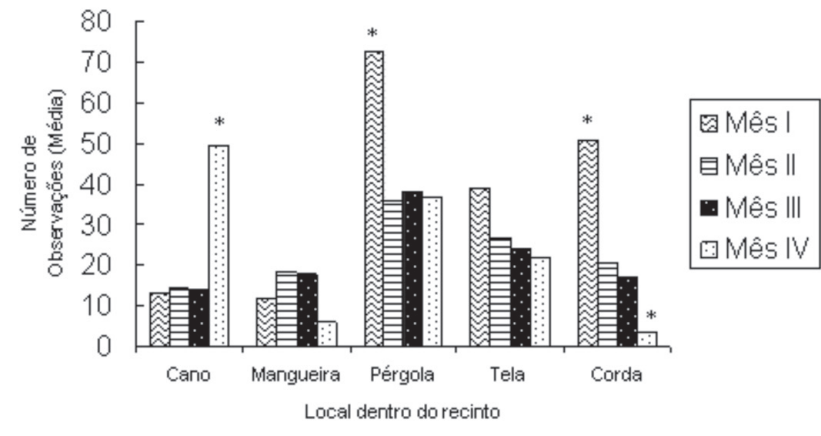

Figura 2 - Representação gráfica da média dos locais mais utilizados pelo infante de Alouatta fusca em cativeiro. Os valores representados pelas barras com asterisco são significativamente diferentes em relação aos demais meses, segundo teste de Wilcoxon $(p<0,05)$.

As estruturas mais utilizadas pelo infante durante suas atividades comportamentais coincidem com locais mais altos dentro do recinto. Brincadeiras de pular e pendurar, repouso, deslocamentos, comportamentos exploratórios foram registrados com maior frequência sobre a pérgola de agosto a novembro/2006 (Figura 2). A proteção e a fonte de termorregulação fornecida ao infante pelo ventre da mãe, principalmente em período chuvoso, o uso deste local, principalmente para brincadeiras de se pendurar e deslocamentos, reflete a maior permanência do infante no cano durante novembro a dezembro/2006 (Figura 2). A utilização de árvores de grande porte para dormir, descansar, forragear, se deslocar, entre outras por bugios em ambientes naturais foi observado por Bonvicino (1989) e Souza (2005). Em relação ao estrato florestal, Ludwig (2006) verificou uma maior utilização do dossel por grupos de bugio (Alouatta caraya).

\section{CONCLUSÕES}

A maior independência e segurança do infante de Alouatta fusca, com o aumento da idade, levaram a um distanciamento da mãe e a exploração de estruturas localizadas em maiores alturas dentro do recinto, como a pérgola, assemelhando a preferência por estratos florestais mais altos, em vida livre. As informações obtidas neste trabalho contribuem para um melhor entendimento em relação aos infantes de Alouatta fusca, suas interaçóes sociais e uso do espaço em cativeiro que podem ser extrapoladas para o ambiente natural devido a grande similaridade com estes padróes. Além disso, estes conhecimentos podem ser utilizados para aprimorar o manejo ex-situ dos animais, criando melhores condiçóes para a estadia dos mesmos em cativeiro, utilizando-se de estruturas adequadas que simulem o ambiente natural, a fim de garantir o bem-estar dos bugios e assim, a sobrevivência da espécie.

\section{BIBLIOGRAFIA CITADA}

Altmann, J. 1974. Observational study of behavior: sampling methods. Behaviour, 40: 227-267.

Altmann, S.A. 1959. Field observations on a howling monkey society. Journal of Mammalogy, 40: 317-330.

Aguiar, L.M.; Ludwig, G.; Hilst, C.L.S.; Malanski, L.S.; Passos, F.C. 2005. Tentativa de infanticídio por um macho dominante de Alouatta caraya (Humboldt) (Primates, Atelidae) em um infante extra-grupo devido a influência do observador. Revista Brasileira de Zoologia, 22 (4): 1201-1203.

Albuquerque, V.J.; Codenotti, T.L. 2006. Etograma de um grupo de Bugios-pretos, Alouatta caraya (Humboldt, 1812) (Primates, Atelidae) em um habitat fragmentado. Revista de Etologia, 8 (2): 97-107.

Baldwin, J.D.; Baldwin, J.I. 1973. Interactions between adult female and infant howling monkeys (Alouatta palliata). Folia Primatology, 20: 27-71.

Bonvicino, C.R. 1989. Ecologia e comportamento de Alouatta belzebul (Primates: Cebidae) na Mata Atlântica. Revista Nordestina de Biologia, 6: 149-179.

Carpenter, C.R. 1934. A field study of the behavior and social relations of howling monkeys. Comparative psychology monographs, 10 (2): 1-168.

Clarke, M.R.; Glander, K. E., Zucker, E.L. 1998. Infant-nonmother interactions of fre-ranging mantled howlers (Alouatta palliata) in Costa Rica. Internacional Journal of Primatology, 19 (3): 451-472.

Gregorim, R. Taxonomia e variação geografia das espécie do gênero Alouatta Lacépède (Primates, Atelidae) no Brasil, Revista Brasileira de Zoologia, 23, 1, 64-144, 2006

Jardim, M.M. 2005. A. Ecologia Populacional de Bugios-Ruivos (Alouatta guariba) nos Municípios de Porto Alegre e Viamão, RS, Brasil. Dissertação de doutorado, Universidade Estadual de Campinas, Campinas. 55 pp.

Lima, E.C. 1944. Mamíferos da Amazônia: introduçóes gerais e primatas. Belém do Pará - Rio de Janeiro, Livraria Agir Editora. $80 \mathrm{pp}$.

Ludwig, G. 2006. Área de vida e uso do espaço por Alouatta caraya (humboldt, 1812) em ilha e continente do alto rio Paraná. Dissertação de mestrado, Universidade Federal do Paraná, Curitiba. 88 pp.

Mack, D. 1979. Growth and development of infant red howling monkeys (Alouatta seniculus) in a free ranging population. p. 127-136. In: JF Eisenberg (Ed). Vertebrate Ecology in the Northern Neotropics. Washington DC: Smithsonian Institution Press, 66 pp.

Mendes, S.L. 1989. Estudo ecológico de Alouatta fusca (Primates: Cebidae) na Estação Biológica de Caratinga, MG. Revista Nordestina de Biologia, 6 (2): 71-104.

Miranda, J.M.D. 2004. Ecologia e Conservação de Alouatta guariba clamitans Cabrera, 1940 em Floresta Ombrófila mista no estado do Paraná, Brasil. Dissertação de mestrado, Universidade federal do Paraná, Curitiba. 50 pp. 
Miranda, J.M.D.; Passos, F. C. 2004. Hábito alimentar de Alouatta guariba (Humboldt) (Primates, Atelidae) em floresta de Araucária, Paraná, Brasil. Revista Brasileira de Zoologia, 21 (4): 821-826.

Miranda, J. M. D.; Agular, L. M.; Ludwig, G.; Moro-Rios, R. F., Passos, F. C. 2005. The first seven months of an infant of Alouatta guariba (Humboldt) (Primates, Atelidae): Interactions and the development of behavior patterns. Revista Brasileira de Zoologia, 22 (4): 1191-1195.

Nantes, R.S.; Rímoli, J. Ecologia e comportamento de bugios pretos (Alouatta caraya, primates, atelidae) em fragmento florestal na margem esquerda do rio Aquidauana, Anastácio, Mato Grosso do Sul. Disponível na World Wide Web em: <http://www. propp.ufms.br/gestor/titan. php?target $=$ openFile\&fileId $=641>$. Acesso em 27/05/2011.

Neville, M. K. 1972. Social relations within troops of red howler monkeys (Alouatta seniculus). Folia primatology, 18: 47-77.
Podgaiski, L.R.; Jardim, M.M.A. 2009. Early Behavioral Development of a Free-Ranging Howler Monkey Infant (Alouatta Guariba Clamitans) in Southern Brazil. Neotropical Primates, 16(1):27-31.

Rylands, A. B.; Keuroghlian. A. 1988. Primate populations in continuous forest and forest fragments in central Amazonia. Acta Amazonica, 18(3-4): 291-307.

Souza, S. P. 2005. Ecologia e conservação de Alouatta belzebul (Primates, Atelidae) na Paraíba, Brasil. Tese de Doutorado, Universidade Federal de Minas Gerais, Belo Horizonte. 104 pp.

Zaccaron, G.S. 2005. Estudo dos aspectos gerais e do comportamento de Alouatta fusca, em um remanescente florestal no município de Morro da fumaça - SC. Monografia, Universidade do Extremo Sul Catarinense, Criciúma. 40 pp.

Recebido em: 22/02/2011

Aceito em: 09/09/2011 
